\title{
FPD with difference in connectors: A case report
}

\author{
Kalamalla A Saran Babu ${ }^{1 *}$, Ponnapalli Haripriya², Srinivas Rao Pottem ${ }^{3}$, Hanuman Chalapathi Kumar Voleti ${ }^{4}$, \\ Pavan Kumar Tannamala ${ }^{5}$
}

\author{
${ }^{1}$ Assistant Professor, ${ }^{2} \mathrm{MDS},{ }^{3}$ Professor and HOD, ${ }^{4,5}$ Professor, ${ }^{\mathbf{1 , 3 - 5}}$ Dept. of Prosthodontics, ${ }^{2}$ Dept. of Oral Pathology, ${ }^{\mathbf{1 , 3}-5} \mathrm{Narayana}$ Dental \\ College and Hospital, Nellore, Andhra Pradesh, ${ }^{2}$ Wisdom Dental Private hospital, Nellore, Andhra Pradesh, India
}

*Corresponding Author: Kalamalla A Saran Babu

Email: ayappasaranbabu@gmail.com

\begin{abstract}
The durability and long term performance of a Fixed Partial Denture (FPD) largely depends on the type of occlusal relationship, area of missing teeth, distribution of stress, alveolar bone loss and condition of the periodontium. The prosthetic reclamation of a posterior FPD with pier abutment is always considered as a challenging task for a dentist due to frequent fracture of posterior FPD in connector region during functional occlusal loading. The frequent use of rigid connectors in day to day practice in such situations results in failure and instability of the prosthesis. In pier abutment areas, replacement of rigid connectors with non rigid connectors during fabrication of an FPD makes a huge difference in the long term mechanical behaviour of posterior fixed dental prosthesis. So, depending on the clinical scenario, accurate prior selection of type of connector by dentist makes the real difference in the overall prosthetic overhaul of the prosthesis. This clinical case report explains the simple basic technique of incorporation of non rigid connector to restore such cases.
\end{abstract}

Keywords: Pier abutment, Connector, Retainer, FPD.

\section{Introduction}

The increase in the fabrication of more and more fixed dental restorations is with the rising demand of aesthetics \& function from both the dentists as well as patients. The longterm mechanical behaviour of the restoration is critical since ceramics exhibit a time-dependent decrease in the strength due to the subcritical crack growth. In general, FPD commonly fracture in the connector region under load application and is related to the size, shape, and position of the connectors and to the span of the pontic. ${ }^{1,2}$ Furthermore, the excessive flexing of the long-span FPD, which varies with the cube of the length of span, can lead to material failure of prosthesis or to an unfavorable response.

The most common clinical scenario, considering a pier abutment, is the replacement of a missing first premolar and first molar, either in the maxillary or mandibular arch, with a FPD design in which the canine and the second molar will be acting as the terminal abutments where as the second premolar serves as a pier abutment. It has been hypothesized that during function there is every chance of de-bonding of the less retentive terminal retainer, namely canine, due to invading of waver movements produced by extreme abutments, thus making the pier abutment to act as a fulcrum and inevitably leading to the failure of the prosthesis. In such situations, designing an FPD with non rigid connectors having a stress breaking mechanical union of retainer and pontic will overcome the potential risks of the prosthesis.

The possible indications of non rigid connectors would be; when it is difficult to prepare two abutments for an FPD with a common path of placement; tilted abutment cases; complex FPD consisting of both anterior and posterior segments etc. In those areas, these types of connectors are indicated to relieve the stress at mid span on long pontics associated with pier abutments. In designing of non rigid connectors, firstly incorporation of prefabricated inserts in the wax pattern or custom milling the castings obtained, then fitting the second part to the milled retainer and cast was done. These second parts are often made with prefabricated plastic patterns where as the retainers are then cast separately and fitted to each other in metal. , $^{3,4}$

The following case report describes the fundamental fabrication technique of key-keyway non rigid connector in mandibular pier abutment situations.

\section{Case Report}

A 45 year old female patient visited department of prosthodontics, Narayana Dental College \& hospital with a chief complaint of difficulty in chewing on right side. No relevant medical history was found to be significant. Intraoral examination revealed, in mandibular arch, there were missing 1st premolar and 1st, 2nd molars on the right side with the remaining 2 nd premolar as pier abutment and 3rd molar as the posterior abutment (Fig. 1). In maxillary arch there was cast partial denture with adequate retention. Similarly patient was $\mathrm{u}$ replaced with a fixed dental prosthesis in mandibular left side region on radiographic examination, Abutment teeth had adequate bone support. Since it was a pier abutment situation on the right side, a 5unit FPD using non-rigid connector was planned to compensate the stress distribution. 


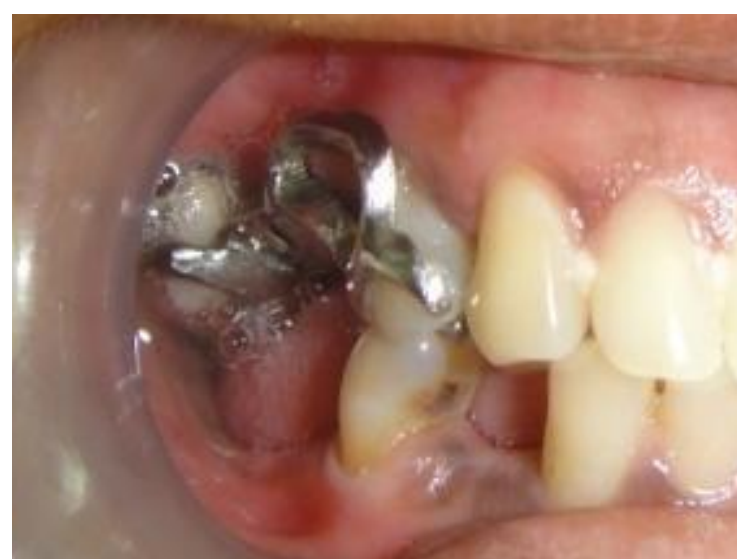

Fig. 1: Intraoral view of pier abutment in mandibular arch

\section{Technique for fabrication of 5 unit FPD using non-rigid} connector

1. Primary impressions for mandibular arch were made with an irreversible hydrocolloid Alginate impression material (Zelgan; Dentsply, India) and diagnostic casts were prepared.

2. Mock tooth preparation was completed on the articulated diagnostic casts and provisional restoration was fabricated.

3. After completion of the tooth preparation for the abutments in relation to canine, $2^{\text {nd }}$ premolar and $3^{\text {rd }}$ molar (Fig. 2), a putty wash impression was made with soft putty and light body impression material (Aquasil, Dentsply, India) and master cast was then poured with type 4 gypsum product

4. During the same appointment, intra oral fit of the temporization fabricated on the mock cast was checked; any relining required was completed; cementation of provisional restoration was completed.

5. Fabrication of a non-rigid connector design involves the following steps: Firstly dove tail design of Key (tenon, male) and keyway (mortise, female) design of non-rigid connector was incorporated in the wax pattern and then followed by investing and casting; After casting, finishing was completed (Fig. 4), metal try in was checked intra orally for proper fit; seating of the framework and individual units of the prosthesis.

6. When checking the intraoral fit of the metal try in, Positioning of key is very critical and its path of placement must be parallel to the distal retainer. Once satisfied with fit and seating of the framework, brisk trail of ceramic followed by glazing should be performed.

7. During cementation, mesial segment was cemented first followed by distal segment (Fig. 6). Care should be taken that no excess cement was placed in the non-rigid connector area. Post insertion occlusion was checked and proper instructions were given (Fig. 7).

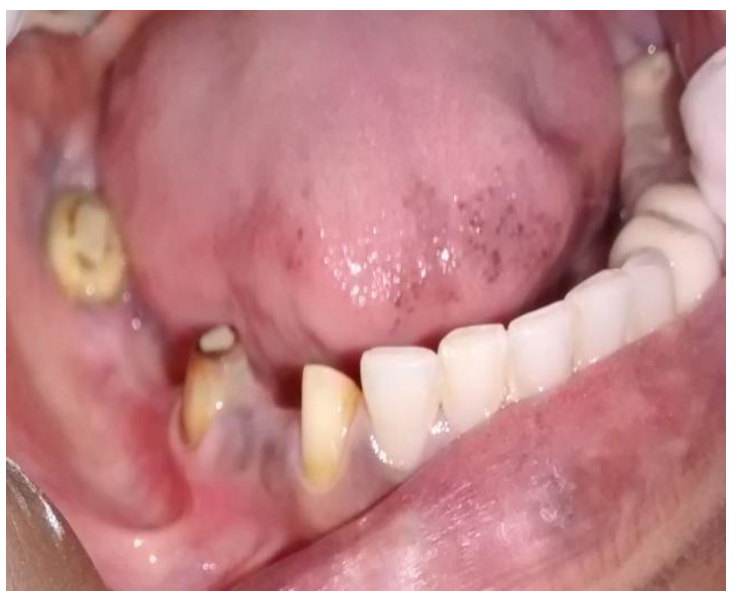

Fig. 2: Tooth preparations irt 13, 15, 18

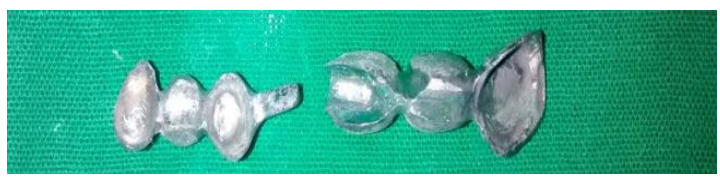

Fig. 3: Castings of male and female portions of non-rigid connector

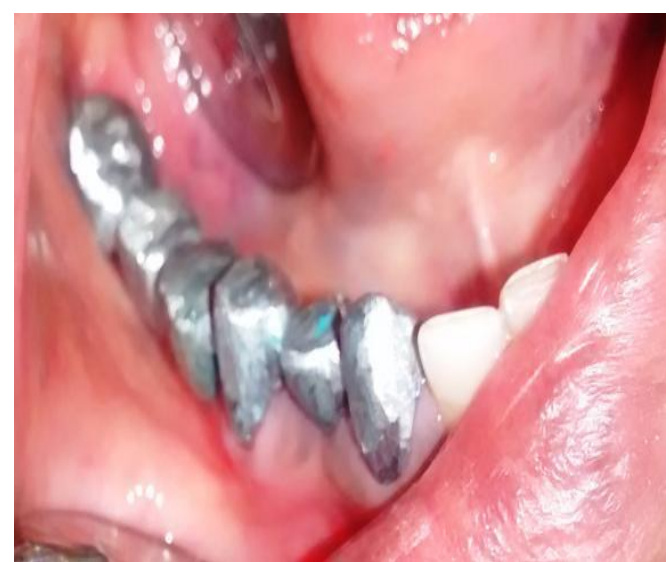

Fig. 4: Metal try in patient's mouth

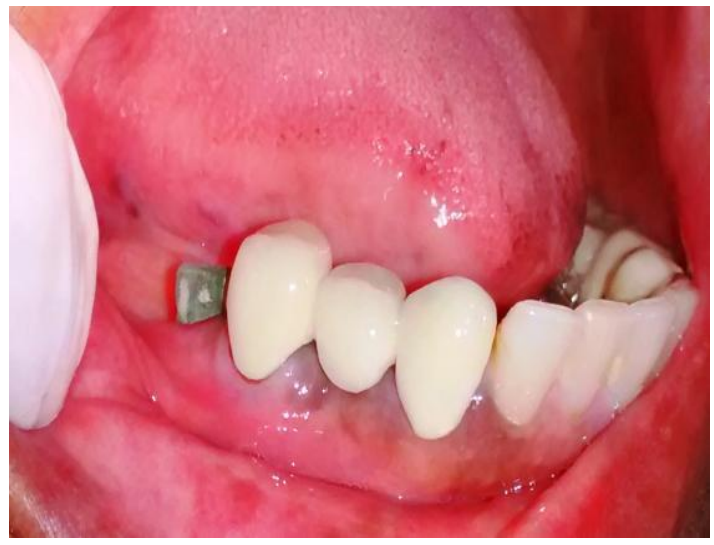

Fig. 5: Cementation of mesial segment 


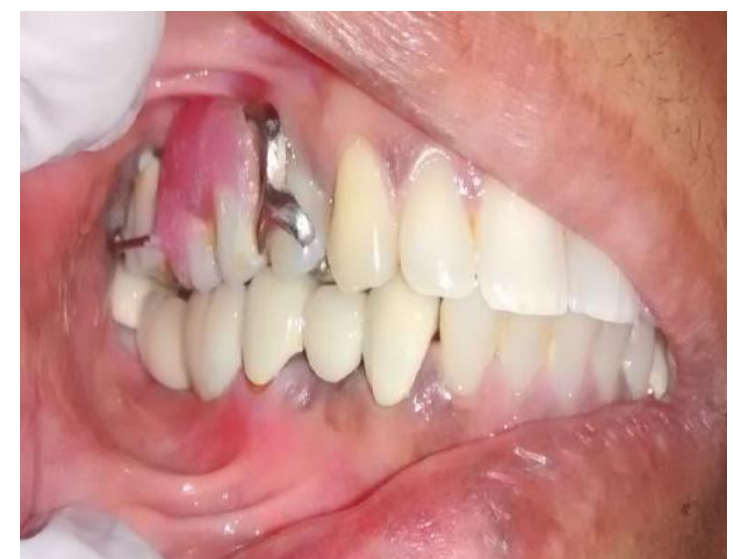

Fig. 6: Cementation of distal segment

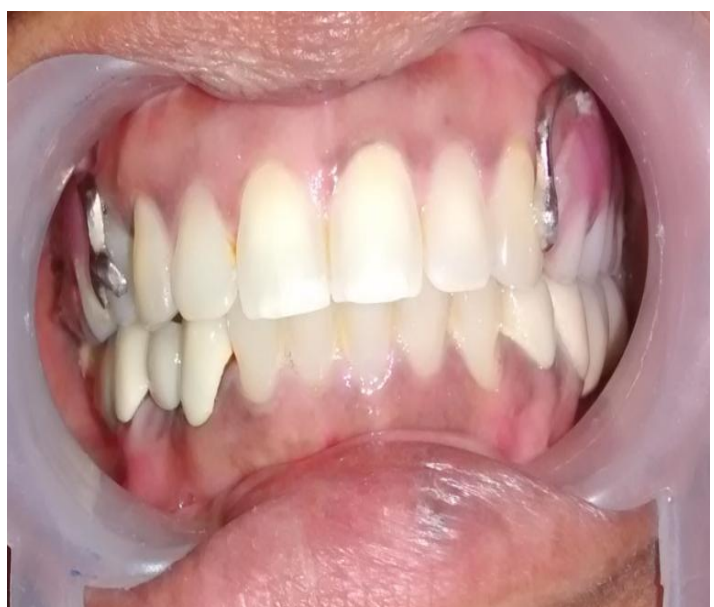

Fig. 7: Post insertion occlusion of fpd with non rigid connector

\section{Discussion}

The clinical fracture resistance and longevity of the fixed dental prosthesis is related to the size, shape and position of the connectors; occlusion, bone loss, quality of periodontium and to the span of the pontic. More over the mechanical behaviour of posterior FPD reveal that the potential fractures occur at the weakest point of the prosthesis, i.e., the connector, regardless of the material used. During functional loading, stress concentration is found in the connectors of the prosthesis and in the cervical dentin area near the edentulous ridge. Biomechanical factors such as overload, leverage, torque and flexing, induce abnormal stress concentration in an FPD. These factors play an important role in the potential failure in long-span FPD.

Considering the high fracture risk rate of the connectors, clinically, the long term mechanical behaviour of an FPD depends on the precise selection of the size, shape and location of the connector. Depending on the clinical scenario, especially in cases like pier abutment and large edentulous space in the anterior region, the regular use of rigid connectors in fabrication of an prosthesis results in its fracture. During functional occlusal loading in posterior FPD with pier abutment, due to teetering movements on the molar retainer and tensile forces on the canine retainer, pier abutment acts a fulcurm and the resultant forces may lead to potential loss of retention for these prosthesis, thus resulting in marginal leakage, caries of abutment, and FDP failure. ${ }^{6,7}$

This clinical case report describes the incorporation of a non-rigid connector in the fabrication of a posterior FPD with pier abutment situations. These connector's acts as stress breaker between retainer and pontic, thus preventing the transfer of stress from segment being loaded to the rest of the FPD. In general, designing of non rigid connector is between distal of second premolar retainer and mesial of first molar pontic where second premolar act as a pier abutment and canine and second molar act as terminal abutments.

In the fabrication of non rigid connector in pier abutment conditions, different authors have proposed various opinions on the placement site of the connector. Different studies include; placement of non-rigid connector on one of the posterior abutments and not at the pier abutment (Markley, 1951) ${ }^{8}$ Placement of non rigid connector at one side or both sides of the pier abutment (Gill, 1952). ${ }^{9}$ Placement of the non rigid connector at the distal side of pier, and if desired, adding one more at the distal side of the anterior retainer (Adams 1956) ${ }^{1}$; placement of the non-rigid connector at distal aspect of pier abutment because placement on either of the terminal abutments could result in the pontic acting as a lever arm (Shillinburg et al, 1997). ${ }^{10}$

Generally alignment of long axis of the posterior teeth will be slightly in a mesial direction, so vertically applied occlusal forces applied in this direction produce further movement, nullifying the fulcrum effect. This makes seating of the key/ male of the attachment firmly in place when pressure is applied distally to the pier abutment. Based on the stress analysis conducted by Orucet in $2008,{ }^{11}$ the area of stress concentration in the pier abutment is reduced when a non-rigid connector was incorporated distal to the pier abutment. Even though fabrication of non-rigid connector is technique sensitive and cumber sum, they confirmed the stress breaking effect caused due to incorporation of these connectors especially in pier abutment situations results in longevity and durability of the prosthesis.

\section{Conclusion}

The future success, longevity and mechanical behavior of fixed prosthesis depend on proper selection of the connector since these areas are main potential risks for fracture propagation. Selection of a non-rigid connectors for pier abutments clinical cases transfer less stress to abutments and also allow physiologic tooth movement thereby increasing the life span of the prosthesis. The proper passive fit of these connectors mainly depends on the accurate planning of the design philosophy which prevents the leverage effect to a large extent and enchases success rate of long span FPD with pier abutments.

\section{Source of funding}

None. 


\section{Conflict of interest}

None.

\section{References}

1. Rosenstiel, Land, Fujimoto-Contemporary fixed and prosthodontics 3 edition, pg. 65-81.

2. Shillinburg HT Jr, Hobo S, Whitsett LD, Jacobi R, Brackett SE. Fundamentals of fixed prosthodontics. 3rd edn. Passi; India; 1997. p. 95-100.

3. Shillingburg HT, Fisher DW. Nonrigid connectors for fixed partial dentures. J Am Dent Assoc 1973;87: 1195-1199.

4. Kumar P. Non-rigid connector in fixed partial dentures with pier abutment: An enigma simplified." Int J Health Allied Sci 2012;1.3:190.

5. Banerjee, Saura. Non-rigid connector: The wand to allay the stresses on abutment. Contemp Clin Dent 2011;2.4:351.

6. Bothello MG, Dyson JE. Long-span fixed movable, resin bonded fixed partial dentures: a retrospective, preliminary clinical investigation. Int J Prosthodont 2005;18:371-6.
7. Markley MR. Broken-stress principle and design in fixed bridge prosthesis. J Prosthet Dent 1951;1:416-23.

8. Gill JR. Treatment planning for fullmouth rehabilitation. $J$ Prosthet Dent 1952;2:230-45.

9. Adams JD. Planning posterior bridges. J Am Dent Assoc 1956;53:647-54.

10. Shillingburg HT Jr, Hobo S, Whitsett LD, Jacobi R, Brackett SE. Fundamentals of fixed prosthodontics. 3rd ed. Chicago: Quintessence; 1997. p. 85-118.

11. Oruc S, Eraslan O, Tukay HA, Atay A. Stress analysis of effects of non rigid connector on fixed partial denture dentures with pier abutments. J Prosthet Dent 2008;99:185-92.

How to cite this article: Saranbabu KA, Haripriya $\mathrm{P}$, Pottem SR, Voleti HCK, Tannamala PK. FPD with difference in connectors: A case report. Int J Oral Health Dent 2019;5(3): 